\title{
DOCUMENTACIÓN ASTUR-LEONESA. ESTUDIO PALEOGRÁFICO-DIPLOMÁTICO DE UN PRIVILEGIO DE ALFONSO III
}

\author{
por \\ JUAN CARLOS GALENDE DÍAZ
}

En una etapa de florecimiento para la Paleografía y la Diplomática, queremos contribuir con un estudio crítico de un documento conservado en la Biblioteca de la Real Academia de la Historia. Documento, por otra parte, que, como veremos más adelante, ha sido objeto de controversia para diferentes especialistas. Nos estamos refiriendo al privilegio otorgado por el rey Alfonso III sobre los arciprestazgos de Besancos, Prucios y Trasancos que se concedieron por permuta a la iglesia de Santiago por los votos que le tocaban en el obispado de Mondoñedo.

La fecha de la escritura de este rey asturleonés, apodado "El Magno", es el año 864, lo cual ya nos indica sobre la antigüedad e importancia del documento en cuestión, que tiene como material soporte el pergamino, obviamente.

En la actualidad esta fuente histórica se encuentra archivada, como ya hemos dicho, entre los numerosos fondos conservados en el citado centro madrileño ${ }^{1}$, en una caja de cartón, forrada con papel de color morado, que atesora, además del escrito objeto de nuestro estudio, diversa documentación, toda ella original manuscrita en pergamino y papel, de naturaleza pública y eclesiástica, como por ejemplo el título de virrey de Nápoles al duque de Osuna don Pedro Girón - fechado en Lisboa el 22 de diciembre

' Biblioteca de la Real Academia de la Historia, signatura 9-4-7/1956, expediente 8.

"CUADERNOS DE ESTUdios GAllegOS", Tomo XLI, Fascículo 106, Santiago 1993-94. 
de 1581-, un privilegio del rey Alfonso III al obispo Rudesindo datado el año $877^{2}$, diferentes cédulas de los Reyes Católicos, testimonios de hidalguía o varias cartas de carácter eclesiástico, tanto apostólicas ${ }^{3}$ como de otras altas dignidades religiosas. La mayoría de estas piezas archivísticas han llegado a la Biblioteca mediante donaciones.

Por lo que respecta a su estado de conservación, se puede catalogar de satisfactorio, a pesar de que las condiciones de mantenimiento no son las más idóneas, ya que las piezas documentales se encuentran todas mezcladas y dobladas con numerosos pliegues, lo que originará su paulatino deterioro ${ }^{4}$. Además, cabe significar, la desaparición por pérdida o sustracción de diferentes sellos de placa y de plomo, que debían estar validando su respectivo documento.

En cuanto al documento objețo de estudio, se encuentra en bastante buen estado de conservación, aunque en su superficie aparecen algunas manchas de humedad y unos rotos, producidos por los múltiples dobleces que tiene; asimismo, y como es usual en la documentación de esta época, el material no es de buena calidad y los bordes están recortados irregularmente.

Otras características archivísticas que podemos apuntar de este documento heterógrafo es que el color de la tinta es sepia y que sus dimensiones absolutas son unos $235 \mathrm{~mm}$. x unos $495 \mathrm{~mm}$., estando la escritura dispuesta a línea tendida, siguiendo la parte más ancha del documento.

Por su parte, los márgenes están bien cuidados, siendo sus medidas las siguientes: entre 15 y $20 \mathrm{~mm}$. el superior, entre 35 y $40 \mathrm{~mm}$. el inferior, entre 10 y $20 \mathrm{~mm}$. el lateral izquierdo y $30 \mathrm{~mm}$. el lateral derecho. Asimismo, los renglones, separados entre sí por un centímetro aproximadamen-

\footnotetext{
${ }^{2}$ Este privilegio, también en latín con letra visigótico-mozárabe, se halla inserto en la obra del padre Enrique FLÓREZ, España Sagrada, tomo XVIII, apéndice, Madrid, pág. 308 , aunque existen algunas variantes entre la transcripción publicada por este prestigioso erutido del siglo XVIII y la escritura conservada en este Centro, pero son pocas y nada esenciales, siendo la más notable la que hay en el nombre del último confirmante, que aquél lee "Ousonius" y en el privilegio se aprecia "Ordonius".

${ }^{3}$ En el conjunto de estas "litterae apostolicae", podemos encontrarlas de los pontífices Inocencio XII o Clemente IX, validadas con el sello de plomo.

${ }^{4}$ Sin duda, es el citado privilegio de Alfonso III al obispo Rudesindo a finales del siglo IX, también en pergamino $(335 \mathrm{~mm}$. x $530 \mathrm{~mm}$.) el que se encuentra en peores condiciones, ya que contiene numerosas lagunas, debidas a rotos, manchas, dobleces, etc. B.R.A.H., signatura 9-5-7/1956, expediente 9.
}

"CUADERnOS DE eStudios GALLEGOS", Tomo XLI, Fascículo 106, Santiago 1993-94. 
te, tienen unas longitud de $450 \mathrm{~mm}$. En total, la caja de escritura tiene unas dimensiones de $180 \mathrm{~mm}$. x $450 \mathrm{~mm}$.

Peculiaridades paleográficas propiamente dichas estarían en relación con la escritura. Lo primero que debemos exponer es que el tipo de escritura empleado para la confección del documento es la denominada visigóticomozárabe ${ }^{5}$ en su modalidad de redonda o sentada. Si tuvieramos que

\footnotetext{
${ }^{5}$ Históricamente, la génesis de esta escritura debe relacionarse con el período correspondiente al reino visigodo de España durante los siglos $\mathrm{V}$ y siguientes, hasta el año 711. Gráficamente, tiene su origen en la escritura nueva romana -en su modalidad de comúnsiendo su evolución la siguiente: surge en el siglo VII, se desarrolla en las centurias posteriores, comienza su decadencia durante el siglo XII y desaparece absolutamente en el siguiente, siendo un documento del año 1234 el último trazado con este tipo de letra. En un primer momento fue una escritura empleada en la confección de códices o libros manuscritos, pero desde muy pronto se incorporó al campo documental. En este último, existe un vacío actual en la conservación de originales de los siglos octavo y noveno -de ahí también la importancia del privilegio de Alfonso III-, pero abundan los de las centurias $\mathrm{X}$ y XI, con variedad de formas gráficas, ya que no se empleó otra ni para los diplomas reales, ni para los documentos de instituciones civiles y eclesiásticas, ni para los de carácter privado. Esta escritura ha sido estudiada por diversos especialistas, entre los que destacan J. ALTURO y A.M. MUNDO, "La escritura de transición de la visigótica a la carolina en la Cataluña del siglo IX", Actas del VIII coloquio del Comité Internacional de Paleografia Latina, Madrid, 1990, págs. 131-138; G. ANTOLIN, "Estudios de códices visigodos", Boletín de la Real Academia de la Historia, LIV (1909); J.M. AZEVEDO, De la visigótica a la carolina. La escritura en Portugal del 882 al 1173, Coimbra, 1988; R.M. BLASCO, "Aproximación a la escritura visigótica en Cantabria. Los documentos conservados en Santillana", Altamira, XLVII (1988), págs. 75-128; C. DEL CAMINO, "Los orígenes de la escritura visigótica: ¿Otras posibilidades para su estudio?", Actas del VIII coloquio del Comité Internacional de Paleografia Latina, Madrid, 1990, págs. 29-38; A. CANELLAS, Diplomática hispano-visigoda, Zaragoza, 1979; M.C. DÍAZ Y DÍAZ, Códices visigóticos en la monarquía leonesa, León, 1983; J.M. FERNÁNDEZ CATÓN, "Documentos leoneses en escritura visigótica", Archivos leoneses, 53 (1973), págs. 99-191, 54 (1973), págs. 203 226, 55 (1974), págs. 31-83 y 72 (1982), págs. 195-292; S. GARCÍA LARRAGUETA, "Consideraciones sobre la datación de códices en escritura visigótica", Actas del VIII coloquio del Comité Internacional de Paleografia Latina, Madrid, 1990, págs. 51-58; J. GIL, Corpus scriptorum muzarabicorum, 2 vols., Madrid, 1973; M. GÓMEZ MORENO, Documentación goda en pizarra. Estudio y transcripción, Madrid, 1966; C. HERRERO, "La letra visigótica en los reinos pirenaicos", Revista de Archivos, Bibliotecas y Museos, 41 (1920), págs. 491-512; M. HERRERO, Colección diplomática del Monasterio de Sahagún (857-1230), León, 1988; A. MARTÍNEZ SALAZAR, "Diplomática gallega. ¿El último representante de la letra visigoda?", Boletín de la Real Academia Gallega, VIII (1913), págs. 49-56; A. MILLARES, Consideraciones sobre la escritura visigótico cursiva, León, 1973; A.M. MUNDO, Los diplomas visigóticos originales en pergamino. Regesto de do-
} 
encuadrarla en un período determinado tendríamos que hacerlo en el segundo, es decir en la etapa de perfeccionamiento ${ }^{6}$, que abarca los redactados desde finales del siglo IX la mitad de la centuria siguiente. Como tal ejemplar, aún está escrito con un ductus pausado, con estilización de los astiles, frecuencia de signos auxiliares y abreviaturas, con los trazos finales de las letras rectos y con la aparición del semicolon para indicar la falta de la sílaba final $U S$. Además de éstas, otras características escriptorias que aparecen en el documento de Alfonso III son que la letra tiende a la verticalidad, descansando todas ellas regularmente sobre la línea del renglón; que la separación de letras y palabras es correcta, siempre que no estén formando ligados o nexos, tan usuales en este tipo de escritura; que el trazo de las letras es algo grueso, con poco contraste, y el módulo mediano; que los desarrollados astiles comienzan por un pequeño remate, mientras que los cortos caídos terminan en un minúsculo apoyo ( 1 - $m$ ); y que no hay ornamentación alguna, a no ser la que le pueda conferir los signos de los testigos y confirmantes.

Analizando la morfología de las letras que configuran el alfabeto empleado para la confección de este documento, no ofrece mayor dificultad de la que por sí posee este tipo escriptorio. Veamos el sencillo alfabeto que se puede obtener de su análisis:

cumentos de la época visigoda, Barcelona, 1970; J. MUÑOZ y RIVERO, Paleografia visigoda, Madrid, 1919; M.I. OSTOLAZA, "La transición de la escritura visigótica a la carolina en los monasterios del reino de León", Actas del VIII coloquio del Comité Internacional de Paleografia Latina, Madrid, 1990, págs. 149-164; J. ROVIRA, "Sobre los orígenes de la visigótica redonda", Cuadernos de Historia de España, 13 (1950), págs. 518; E. SAEZ, Colección documental del Archivo de la Catedral de León (775-1230). I (775-952), León, 1987; L. SCHIAPARELLI, "Note paleographiche intorno all'origine della scrittura visigoda", Archivo Storico Italiano, $7^{\mathrm{a}}$ serie, 12 (1929), págs. 165-207; I. VELÁZQUEZ, Las pizarras visigodas. Edición crítica y estudio, Murcia, 1989; J. VIVES, Inscripciones cristianas de la España romana y visigoda, 2ª ed., Barcelona, 1969; J. WILliAMS, Manuscrits espagnols du Haut Moyen Age, París, 1977. Además, autores como G. BATTELLI, Z. GARCÍA VILLADA o el mismo A. MILLARES, le dedican diversos temas en sus conocidos manuales paleográficos, en los que se puede encontrar amplia bibliografía.

${ }^{6}$ La división en períodos de la escritura visigótica-mozárabe, tradicional entre los modernos paleógrafos, se debe al alemán E.A. LOWE, quien en su Studia paleographica. A contribution to the history of early Latin minuscule and to the dating of visigothic manuscripts (Munich, 1910), divide su evolución gráfica en 4 etapas, aunque propiamente se refiere a la escritura de códices.

"CUADERNOS DE ESTUDIOS GALLEGOS", Tomo XLI, Fascículo 106, Santiago 1993-94. 


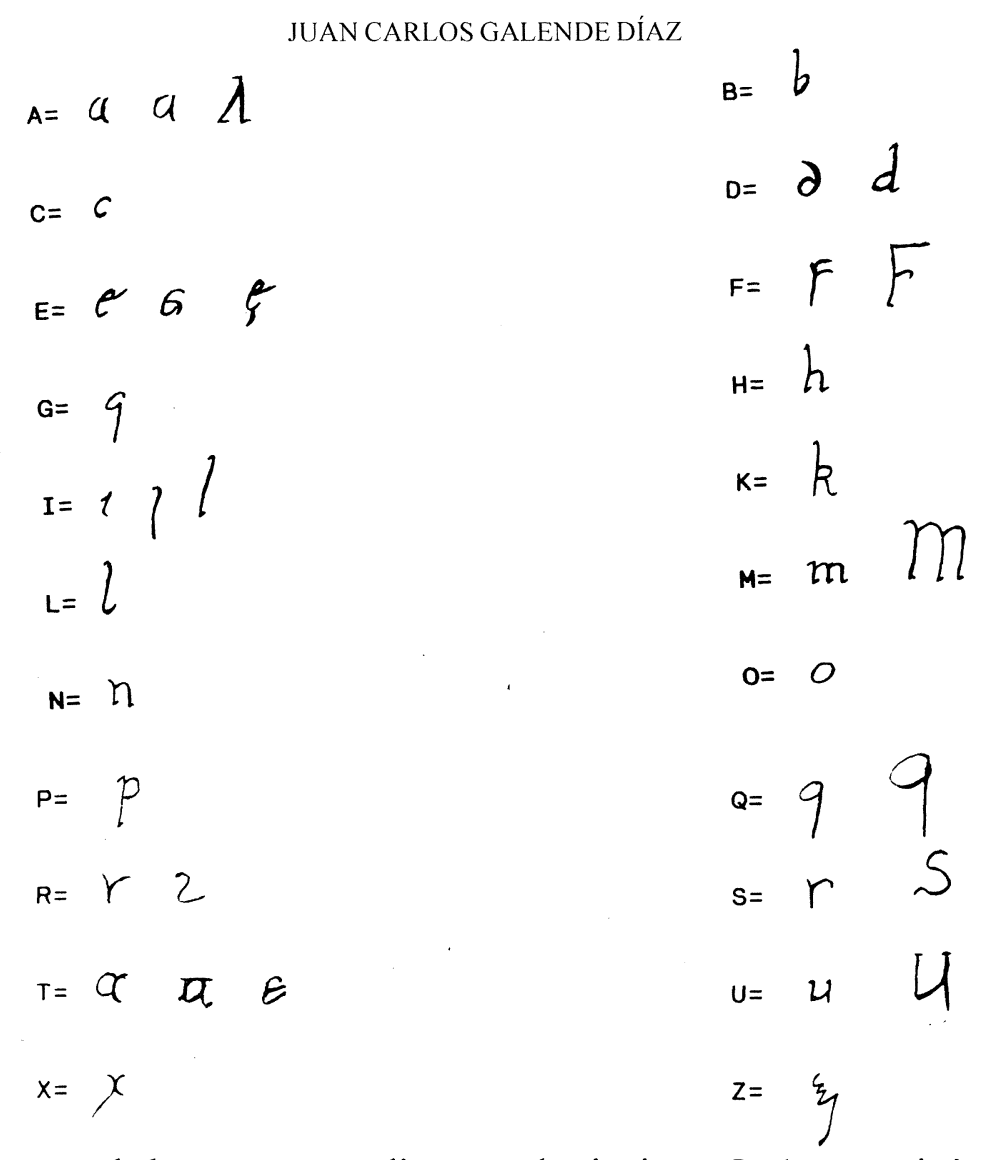

A tenor de lo expuesto expliquemos lo siguiente. La letra $a$ minúscula está formada por dos golpes de pluma que se unen siempre por la parte inferior a modo de un arco más o menos ondulado, mientras que por arriba, no se llegan a tocar, aunque se aproximen; se podría equivocar con la $u$, pero en la $a$ el segundo trazo se encurva para unirse a la letra siguiente, mientras que el de la $u$ cae recto; la forma mayúscula queda abierta por la base. La $b$ y la $c$ no plantean problemas, puesto que son muy semejantes a las actuales. La letra $d$ presenta dos formas: una, de tipo uncial, que vuelve su trazo alto hacia la izquierda, y otro, similar a la actual de imprenta, que mantiene recto y vertical el astil. La $e$ tiene cierta analogía con la contemporánea, aunque en ocasiones lleva un signo en la parte inferior, a modo de cedilla, que sirve para indicar la sílaba ae, denominándose entonces "e caudada". La $f$ es parecida a la nuestra de imprenta tanto en su modalidad de mayúscula como de minúscula, aunque en ocasiones se puede confundir con la $s$, pero ésta es más corta y sin la traviesa intermedia. La $g$ tiene como características principales que la panza o lazo que forma la cabeza

"CUADERNOS DE ESTUdiOS GALLEGOS", Tomo XLI, Fascículo 106, Santiago 1993-94. 
queda abierto y que el trazo inferior cae recto, por lo que puede equivocarse con la $q$, pero en ésta se cierra la parte inferior. La $h$ es parecida a la actual. La $i$ se presenta de tres formas diferentes: una corriente o corta, semejante a la usada hoy; otra, alargada o baja, que cae de la caja del renglón; y una tercera, alta, que se emplea para la forma mayúscula o cuando es comienzo de palabra. La $k$, por su parte, adopta una forma "sui generis". La $l$ puede equivocarse con la $i$ alta, pero se distingue de ella en la pequeña curva que tiene en la parte inferior. La $m, n, o$ y $q$, muy parecidas a las actuales, tanto en sus formas mayúsculas como minúsculas. La $r$ se presenta en su doble modalidad: cuadrada o redonda, pudiéndose equivocar con la $s$, aunque la $r$ se une siempre a la letra siguiente y la $s$ no. La $s$ minúscula es parecida a la $r$, pero su trazo terminal suele formar un pequeño arco hacia abajo; como es lógico, poco tiene que ser con la actual y plantea dificultades de lectura; la s mayúscula es de las denominadas de "doble curva". La $t$ es sin duda la letra más difícil de reconocer por ser diferente a la actual, siendo la primera de las formas que nos aparecen en el documento similar a una $t$ uncial cuya traviesa o trazo horizontal se curvara hacia la izquierda, configurando un semicírculo que descansa en la línea del renglón, y la otra a dos $t$ seguidas. La $u$, semejante a la empleada en la actualidad en sus modalidades de capital y minúscula. La $x$, como la actual más o menos, a modo de aspa pero con el trazo primero desbordando la caja del renglón. La $z$ adopta una forma muy extraña, si la comparamos con las diversas maneras de trazarla en la actualidad.

Analizado el alfabeto, pasemos a continuación a estudiar los nexos y ligados, es decir, las uniones de dos o más letras en función de su intencionalidad o naturalidad, respectivamente. En el documento objeto de estudio no son muy abundantes, siendo los más usuales los conformados por las letras $r$ y $t$ :

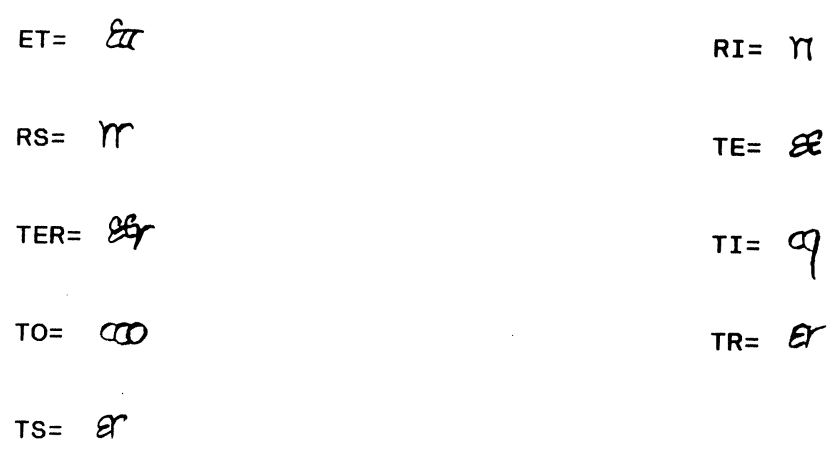

"CUADERNOS DE ESTUDIOS GALLEGOS", Tomo XLI, Fascículo 106, Santiago 1993-94. 
En el campo de la braquigrafía, encontramos múltiples abreviaturas, tanto formadas por suspensión (la palabra abreviada conserva siempre, por lo menos, su primera letra, y le falta siempre, por lo menos, la última) como por contratación (la palabra abreviada conserva siempre, por lo menos, su primera y última letra). Veamos las incluidas en el documento de Alfonso III:

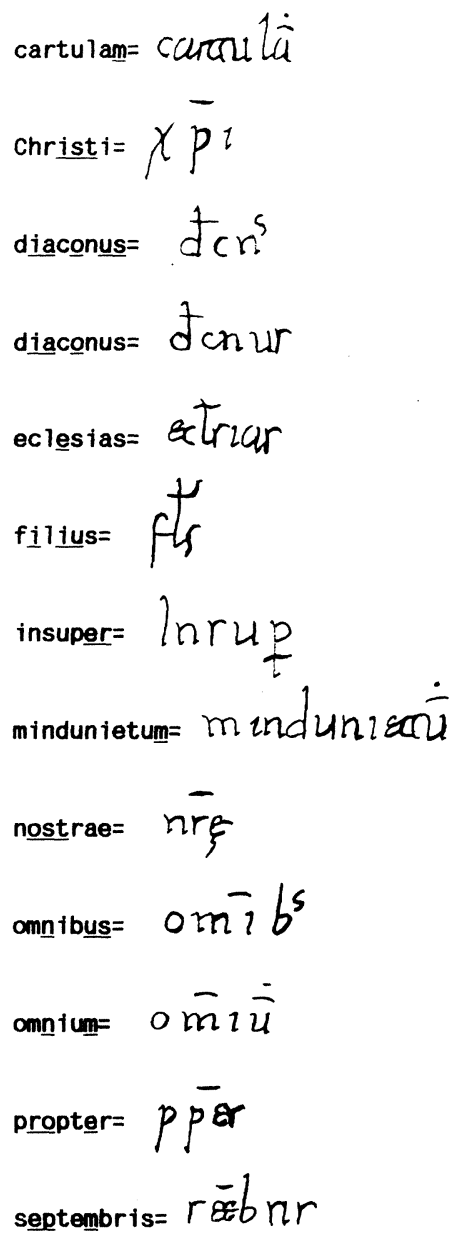

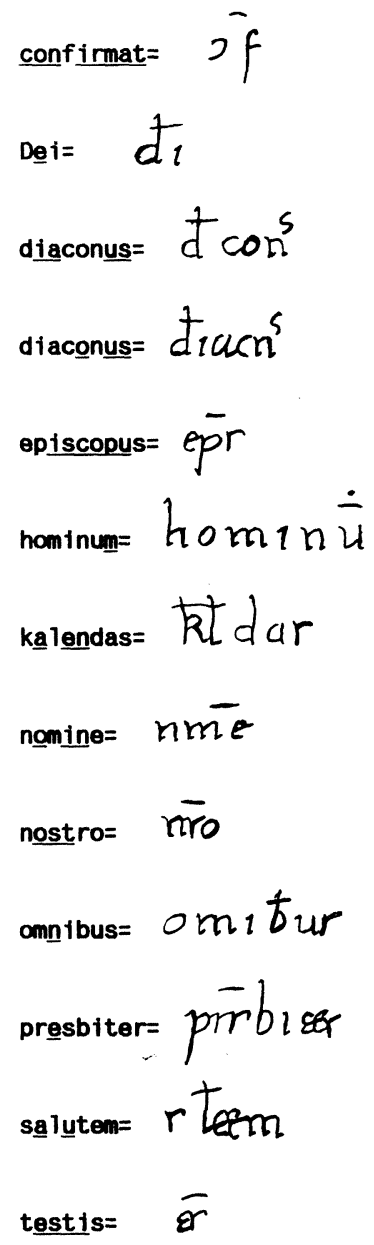


Sobre ellas dos anotaciones. Obsérvese la diversidad de formas empleadas para configurar la abreviatura de diaconus y la estructuración de la abreviatura de Christi, a base de la $\chi$ y la $\rho$ griega, por lo que se transcribe con $C h r$.

En cuanto a signos abreviativos, pueden ser generales - con un significado genérico-, y especiales o específicos — con un significado concreto- - Respecto al primero, se reduce en este documento a una sola raya horizontal corta o con un punto encima, colocado regularmente sobre la letra que inciden: - - . Por su parte, son cinco los signos abreviativos específicos empleados para elidir determinadas letras: $\xi=$ debajo de la letra $e$ una especie de cedilla que sirve para significar la sílaba $a e ; b^{5}=$ sobre la caja del renglón aparece una pequeña $s$ que suple la sílaba $u s ; \forall+=$ la letra $r$ lleva su rasgo final atravesado por una raya recta algo inclinada que elide las letras $u m ; f=$ la letra $p$ lleva en su caído un signo que lo corta en horizontal para indicar que se trata de la abreviatura per; $J=$ un signo semejante a una $c$ invertida sirve para elidir la sílaba con.

Por lo que se refiere a otros signos auxiliares, como los de puntuación, significar que nos aparecen tres. En primer lugar un punto ubicado en la parte baja del renglón, equivalente a nuestra coma o pausa breve. En segundo, un punto encima de otro, comparable a nuestros dos puntos o punto y seguido. Por último, una pequeña $s$ invertida encima de un punto (?), análogo a nuestro punto y seguido.

Importante también apuntar que en el dorso del documento se hallan tres breves notas de registro posteriores a su hechura, ya que están realizadas en el siglo XIV, XV y XVII con letra precortesana, cortesana y humanística cursiva, respectivamente.

Analizadas las peculiaridades paleográficas, pasemos a examinar las diplomáticas. Comenzaremos indicando que nos encontramos ante un privilegio de Alfonso III, es decir un docùmento astur-leonés, o lo que es lo mismo, un original singular, ya que hasta el siglo $\mathrm{X}$ no se conserva prácticamente ninguno, poco más de una veintena, debido a la vida agitada e inestable, en continua acción bélica y migratoria, de toda la población?

\footnotetext{
${ }^{7}$ Sobre este tema se puede consultar la obra dirigida por T. MARIN y J.M. RUIZ ASENCIO, Paleografía y Diplomática, $3^{\text {a }}$ ed., vol. 2, Madrid, 1988, págs. 269-278. Estudios más especializados sobre la documentación astur leonesa son, entre otros, los de L. BARRAU-DIHIGO, "Etudes sur les actes des rois asturiens", Revue Hispanique, 3 (1921); M.J. CARBONELL y F. GIMENO, "El documento astur-leonés: bibliografía (1950-1981), Boletín de la Sociedad Castellonense de Cultura, LVIII (1982), págs. 549-568; A.
}

"CUADERNOS DE ESTUDIOS GALLEGOS", Tomo XLI, Fascículo 106, Santiago 1993-94. 
Además, este documento presenta alguna peculiaridad, no muy frecuente en los escritos de la época, que veremos seguidamente.

La disposición del texto a lo largo del pergamino es bastante correcta: arriba, a línea tendida, los seis renglones del texto, y posteriormente, en cuatro columnas, las líneas de confirmantes y testigos, todo bien distribuido.

Llegados a este punto, creemos que es el momento más oportuno para transcribir literalmente el diploma expedido por Alfonso III, redactado en un latín vulgar, como podremos comprobar:

"In Dei nomine. Ego Adefonsus totius Ispanie imperator qui licet indigne uocitor catholicus tibi Sauarico. Salutem. Michi et omnibus Ispaniae principibus satis notum et propter sarracenorum persecutionem / te a sede tua discessisse et sedem in loco qui Mindunietum uocatur fundasse, me concedente et coroborante. Qua propter concedimus tibi et successoribus tuis diocesim illam que uocatur Trasancos et Besaucos / et Prucios cum omnibus terminis suis procedentibus usque ad aquam de Iunkeras, insuper addimus tibi illas eclesias de Salagia per aquam de discessu usque ad montem que uocatur Nemi, et hec supra dicta / tibi confirmamus propter diocesim de Asturias quam [o]uetensi sedi prebuimus, et deinceps de nostro iure et dominio omnium hominum radimus ut habeas tu et successores tui in integrum. Si quis tamen huius / scripture nostrae seriem infringere conatus fuerit excomunicationis crimen incurrat, insuper centum auri talenta coactus exsoluat presuli eiusdem sedis

COTARELO, Historia crítica y documentada de la vida y acciones de Alfonso III el Magno: último rey de Asturias, Madrid, 1934; Estudios sobre la monarquia asturiana. Colección de trabajos realizados con motivo del XI centenario de Alfonso II el Casto, Oviedo, 1949; A.C. FLORIANO, Diplomática española del período astur. Estudio de las fuentes documentales del Reino de Asturias (718-910), 2 vols, Oviedo, 1949-1951; P. FLORIANO, "Los documentos reales del período astur. Su formulario", Asturiensia Medievalia, 1 (1972), págs. 157-176; M.G. MARTÍNEZ, "Las instituciones del reino astur a través de los diplomas (718-910)", Anuario de Historia del Derecho Español, XXXV (1965), págs. 59-196; E. SAEZ, "Documentos gallegos inéditos del período astur", Anuario de Historia del Derecho Español, XVII (1947), págs. 399-431, y "Nuevos documentos inéditos del reino de Asturias", Revista Portuguesa de Historia, III (1945), págs. 162-176; y C. SÁNCHEZ ALBORNOZ, "Serie de documentos inéditos del reino de Asturias", Cuadernos de Historia de España, 1-2 (1944), págs. 298-351.

"CUADERNOS DE ESTUDIOS GALLEGOS", Tomo XLI, Fascículo 106, Santiago 1993-94. 
menduniensis. Facta cartula $X^{\circ}$ kalendas septembris / era DCCCCII. Adefonsus dei dextera erectus princeps hanc cartulam testamenti a nobis factam. (monograma) /

( ${ }^{a}$ columna) Chrismon, sub Christi nomine Felemirus episcopus, confirmat (signo). Chrismon, sub Christi nomine Nausti episcopus, confirmat (signo). Chrismon, sub Christi nomine Athaulfus episcopus, confirmat (signo).

(2 ${ }^{a}$ columna) Chrismon, Didacus presbiter, testis (signo). Chrismon, Purizellus, testis (signo). Chrismon, Argiricus filius Ariani, testis (signo).

( $3^{a}$ columna) Chrismon, Nepocianus diaconus, testis (signo). Chrismon, Iustus presbiter, testis (signo). Chrismon, Argimirus notarius, testis (signo).

(4 ${ }^{a}$ columna) Chrismon, Olerius diaconus, testis (signo). Chrismon, Ualaminus diaconus, testis (signo). Chrismon, Aloitus diaconus, testis (signo).

(Encima de la $4^{a}$ columna) Felix nomine cognomento busianus hanc cartulam notuit (signo) ${ }^{8}$.

Transcrito este breve y sencillo privilegio, analizaremos la estructura documental de esta interesante fuente para la historia gallega, fechado el año 864 (era hispánica de 902). La primera novedad importante que nos ofrece aparece en el protocolo, puesto que sólamente encontramos invocación verbal ("In Dei nomine") faltando la, absolutamente indispensable, simbólica; luego hallamos la intitulación y la dirección ("Ego Adefonsus... tibi Sauarico ${ }^{19}$ ), para concluir esta primera fase con la fórmula de la salutación ("Salutem"), nada corriente en esta primera etapa de la documentación artus-leonesa. Por su parte, el texto o cuerpo empieza con la exposición de motivos que han llevado al autor a realizar el documento ("Michi

\footnotetext{
${ }^{8}$ Se encuentra incluido este privilegio en la obra citada del historiador burgalés Enrique FLÓREZ (tomo XVIII, Apéndice, pág. 307). Hablando de él, el P. Flórez enmienda la data, opinando que debe leerse DCCCCV en lugar de DCCCCII, y además, el día de las calendas es en la copia de la España Sagrada el V, mientras que en la escritura de que se ha sacado esta, el X; acerca de este punto, este autor refiere en la pág. 62 del mismo tomo la variedad de copias.

${ }^{9}$ Sobre el obispo Sabarico se trata en la página 60 del tomo citado de la obra del P. Flórez.
}

"CUADERNOS DE ESTUDIOS GALLEGOS", Tomo XLI, Fascículo 106, Santiago 1993-94. 
et omnibus Ispanie principibus... in loco qui Mindunietum uocatur fundasse, me concedente et coroborante"), para seguir con la parte esencial del documento, la disposición, es decir, donde se especifica el hecho jurídico que da a aquél su razón de ser ("Que propter concedimus tibi et successoribus tuis diocesim illam que uocatur Trasancos et Besaucos et Prucios cum omnibus terminis suis... et deinceps de nostro iure et dominio omnium hominum radimus ut habeas tu et succesores tui in integrum"); termina esta segunda fase con sendas cláusulas sancionativas penales, una de carácter espiritual ("excomunicationis crimen incurrat") y otra pecuniario ("centum auti talenta"), introducidas por la fórmula "si quis tamen huius scripture nostrae seriem infringere". Por último, en la tercera parte, el escatocolo, aparecen las dos fases fundamentales: la data y la validación; en cuanto a la primera, sólo cronológica (" $X^{\circ}$ kalendas septembris era DCCCCII"), mientras que la validación está compuesta por lo que resta del documento, entre los que podemos destacar el monograma real, las cuatro columnas de confirmantes y testigos (precedido cada nombre del crismón correspondiente, muy estilizado y cursivo, y seguido de su signo propio), y el nombre y signo del notario.

Como conclusión a este estudio, dejar constancia de que por esta escritura se puede comprobar la corrección hecha con sana crítica por el P. Flórez en el texto de sus copias, pues leyéndose en estas "propter diocesim de Asturias quam lucensi sedi probuimus", corrigió "ovetensi sedi"; en este diploma se lee claramente en el cuarto renglón "uetensi", destruida la " $O$ " inicial por un pliegue del pergamino, y conservándose sólo de ella la parte inferior derecha, si bien sobre esta palabra se sustituyó con letra moderna "lucensi", que después fue tachada, y puesta por debajo de la primitiva, que por fortuna siempre se respetó, la misma "ovetensi". Asimismo, en el primer renglón nos aparece sobrepuesto, con grafía moderna, los vocablos "salutem" y "michi" sobre los originales. Acciones reprochables, y que nunca se debieran producir, ya que se deben conservar todas las fuentes documentales como fueron expedidas en su momento. 